\title{
Reflections on a medical career: mistakes made and lessons learned
}

\author{
James R. Scott, MD, ${ }^{1,2}$
}

Key Words: lowa, medicine, physicians

lowa is different. The University, the Medical School and the Department of Obstetrics and Gynecology have been good to many of us here today. My career began here, and I am grateful for the opportunity and training I received. Stories, foibles and a few pearls from those days and my own journey over the years may be useful as you plan your own careers. Superb academic departments are committed to excellence in patient care, research programs that produce new knowledge, and training medical students and residents to be exceptional physicians.

Medicine is a great profession and a special kind of human endeavor that requires compassion, judgment and intellectual honesty, whether in academic medicine or private practice. Impressive technical advances have been made that are dramatically improving patient care, and they will continue in the future. Yet physicians and the public are increasingly frustrated and dissatisfied with the present medical care system. In my view, the practice of medicine is in danger of becoming too complicated, too impersonal and too commercialized. What patients expect from their physicians has not changed over the years; they want a physician they trust, is thorough, friendly, empathetic, takes time and who explains things. In other words, in this era of evidence-based medicine the art of medicine (personalized care) is alive and well, and it is still important.

A number of changes in medicine have taken place over the years that have placed physicians and patients in untenable positions. Factors often overlooked include the profit motive, a

${ }^{1}$ Department of Obstetrics and Gynecology, The University of Utah, Salt Lake City, UT, 84132. ${ }^{2}$ Editor, Obstetrics \& Gynecology, 423 Wakara Way, Suite 201, Salt Lake City, UT 84108

Please cite this paper as: Scott JR. Reflections on a medical career: mistakes made and lessons learned. Proc Obstet Gynecol. 2011 November;2(2):Article 13 [2 p.]. Available from: http://ir.uiowa.edu/pog/. Free full text article.

Corresponding author: James R. Scott, MD, Editor, Obstetrics \& Gynecology, 423 Wakara Way, Suite 201,Salt Lake City, UT 84108, Ph. (801) 583-6000, Fax: (801) 583-6010, jscott@greenjournal.org

This is an Open Access article distributed under the terms of the Creative Commons Attribution 3.0 Unported License (http://creativecommons.org/licenses/by/3.0), which permits unrestricted use, distribution, and reproduction in any medium, provided the original work is properly cited. 
"shortcut mentality", time diverted from patient care (regulations \& paperwork), medical legal issues and a lack of physician input, all driven by external sources such as the political system, insurance companies, and a variety of non physician managers and consultants. What can we do ourselves to assure that Medicine does not lose its purpose and retains its status as a respected profession? I contend that we should re-emphasize excellence and our traditional role as the patient's advocate. Outstanding physicians understand what patients need, and they are willing to go out of their way to achieve it. They are skilled at doing simple things that are valued by patients and their families. These include taking personal responsibility for the patient's care, following evidence based guidelines, listening, remaining accessible, and maintaining patient continuity. They are appropriately cautious about managing patients in common "red flag" situations: treating by telephone, the emergency room, L\&D intake room, delivery room, operating room, early discharge, handoffs/coverage. Finally, they avoid questionable and unproductive activities such as self-promotion, financial ties with pharmaceutical companies and industry, and other conflicts of interest.
Medicine is a privilege. It is a profession, not a business or just a job. Our focus should be on education, research and patient care. Physicians who take the high road, maintain their integrity and enjoy good physicianpatient relationships, will be rewarded by personal satisfaction and revered by their patients. 